\title{
Adjusted Indirect Comparison Using Propensity Score Matching of Osimertinib to Platinum-Based Doublet Chemotherapy in Patients with EGFRm T790M NSCLC Who Have Progressed after EGFR-TKI
}

\author{
Helen Mann ${ }^{1}$ (1) $\cdot$ Frank Andersohn ${ }^{2,3} \cdot$ Carolyn Bodnar $^{1} \cdot$ Tetsuya Mitsudomi $^{4}$. \\ Tony S. K. Mok ${ }^{5} \cdot$ James Chih-Hsin Yang ${ }^{6,7} \cdot$ Christopher Hoyle $^{1}$
}

Published online: 15 December 2017

(c) The Author(s) 2017. This article is an open access publication

\begin{abstract}
Background and objective An adjusted indirect comparison was conducted to assess efficacy outcomes, particularly overall survival (OS), of osimertinib versus platinumbased doublet chemotherapy in patients with epidermal growth factor receptor-mutated (EGFRm) T790M mutation-positive non-small-cell lung cancer (NSCLC) who had progressed following an EGFR tyrosine kinase inhibitor (TKI). Analysis of treatment effect from two separate trials had the potential to more accurately estimate the magnitude of OS benefit due to absence of confounding due to treatment switching from the control arm to the osimertinib arm of the ongoing randomized control trial, AURA3.
\end{abstract}

Electronic supplementary material The online version of this article (https://doi.org/10.1007/s40261-017-0611-3) contains supplementary material, which is available to authorized users.

Helen Mann

helen.mann@astrazeneca.com

AstraZeneca, Cambridge, UK

2 Frank Andersohn Consulting and Research Services, Berlin, Germany

3 Institute for Social Medicine, Epidemiology and Health Economics, Charité University Medicine, Berlin, Germany

4 Division of Thoracic Surgery, Department of Surgery, Faculty of Medicine, Kindai University, Osaka-Sayama, Japan

5 Department of Clinical Oncology, State Key Laboratory of South China, Hong Kong Cancer Institute, Prince of Wales Hospital, The Chinese University of Hong Kong, Sha Tin, Hong Kong

6 National Taiwan University Hospital, Taipei 100, Taiwan

7 Present Address: Eisai Europe Ltd, Hatfield, UK
Methods Two non-randomized individual datasets were compared: pooled patients from the AURA extension and AURA2 trials (osimertinib $80 \mathrm{mg}, n=405$, with a confirmed T790M mutation using tissue samples), and patients from the control arm of the IMPRESS study (platinumbased doublet chemotherapy, $n=61$, with a confirmed T790M mutation using plasma circulating tumour DNA [ctDNA]). A propensity score-based approach was used to account for differences in baseline demographics and disease characteristics.

Results After adjustment for baseline differences between the two groups, osimertinib demonstrated a statistically significant improvement in progression-free survival (PFS) versus platinum-based doublet chemotherapy (hazard ratio $[\mathrm{HR}]=0.278,95 \%$ confidence interval $[\mathrm{CI}]$ 0.188-0.409, $p<0.0001$; median PFS 10.9 vs. 5.3 months). Improvements were also observed for objective response rate (ORR) and disease control rate (DCR) (ORR: 64.3 vs. $33.3 \%$; odds ratio $[\mathrm{OR}]=5.31$, 95\% CI 2.47-11.40, $p<0.001$; DCR: 92.1 vs. $75.0 \%$; $\mathrm{OR}=4.72,95 \% \mathrm{CI}$ $1.92-11.58, p<0.001)$. Similar results were obtained for patients who received osimertinib as second-line treatment only. A statistically significant improvement in OS was observed for the osimertinib group (HR $=0.412,95 \% \mathrm{CI}$ $0.273-0.622, p<0.0001)$. Median OS for osimertinib was not reached.

Conclusions In this indirect comparison, osimertinib showed a statistically significant improvement in efficacy outcomes versus platinum-based doublet chemotherapy in patients with EGFRm T790M NSCLC who had progressed after EGFR-TKI therapy. 


\section{Key Points}

In this adjusted indirect comparison, which assessed efficacy outcomes of osimertinib versus platinumbased doublet chemotherapy in patients with EGFRm T790M NSCLC who had progressed after EGFR-TKI therapy, osimertinib showed a statistically significant improvement in PFS, ORR and DCR compared with platinum-based doublet chemotherapy.

Our analysis has demonstrated outcomes consistent with randomized data from the phase III AURA3 trial (NCT02151981).

\section{Introduction}

The majority of epidermal growth factor receptor-mutated (EGFRm) patients with locally advanced or metastatic nonsmall-cell lung cancer (NSCLC) treated with an EGFR tyrosine kinase inhibitor (TKI) ultimately develop acquired resistance and generally progress within 1 year [1-3]. The median survival of patients after the emergence of acquired resistance is generally less than 2 years [4].

One of the main pathways for development of drug resistance to first- and second-generation EGFR-TKIs is the emergence of a second point mutation resulting in substitution of threonine with methionine at amino acid position 790 at exon 20 (T790M) [5-7]. The T790M point mutation is found in approximately $50-60 \%$ of all patients at the time of acquired resistance to EGFR-TKI therapy $[4,8]$. Prior to development of osimertinib, there were no approved therapies that specifically targeted the acquired T790M mutation. Instead, therapeutic options for patients progressing with EGFR T790M mutation-positive NSCLC were limited to platinum-based doublet chemotherapy, salvage chemotherapy (approved for use after failure of platinum-based doublet chemotherapy), investigational agents and combinations, EGFR-TKI re-challenge, and best supportive care-all of which are associated with limited efficacy [9-18].

Osimertinib is an oral, potent, selective, irreversible EGFR-TKI, active against both EGFRm (TKI sensitivityconferring mutations) and T790M mutation-positive (TKI resistance-conferring mutation) forms of EGFR [19]. Early approvals of osimertinib ( $80 \mathrm{mg}$ once daily) in North America, Europe and Asia have been based on evidence from two phase II single-arm trials, the extension phase of the AURA trial (NCT01802632) and AURA2 (NCT02094261) [19-22]. More recently, randomized data from the confirmatory AURA3 study (NCT02151981) have become available and demonstrated a significant improvement in progression-free survival (PFS) for osimertinib compared with platinum-based therapy plus pemetrexed in patients with EGFR T790M mutation-positive NSCLC [23, 24].

In addition to randomized efficacy data, adjusted indirect comparisons using patient-level data can be used to determine valid estimates of treatment effect. These analyses have the utility to provide additional evidence for reimbursement assessments to support launches based only on single-arm trials; to provide validation and supportive evidence for comparative endpoints in preparation for when randomized controlled trials do become available; and to support those studies where long-term comparative efficacy data may never be available due to the ability of patients to switch to the trial treatment (a growing trend in oncology). This is applicable to osimertinib given that switching treatment is allowed in the AURA3 trial; therefore, the overall survival (OS) hazard ratio (HR) from an adjusted indirect comparison would be important.

To perform an adjusted indirect comparison, we used the control arm (platinum-based doublet chemotherapy and placebo) of the IMPRESS study (NCT01544179), which included a subgroup of patients with the T790M mutation (as identified by plasma-circulating tumour DNA [ctDNA]) and disease progression following response to EGFR-TKI [25]. These patients have similar demographic and disease characteristics to those in the AURA extension and AURA2 trials of osimertinib and represent a valid comparator to demonstrate differences in efficacy outcomes for osimertinib versus platinum-based doublet chemotherapy. Using these populations, we report on a non-randomized, adjusted comparison of efficacy outcomes of osimertinib versus platinum-based doublet chemotherapy for treatment of patients with EGFR T790M mutation-positive advanced NSCLC who have progressed following EGFR-TKI.

\section{Methods}

\subsection{Study Designs}

The efficacy of osimertinib relative to platinum-based doublet chemotherapy was assessed using an adjusted indirect comparison of two datasets comprising patients with a confirmed T790M mutation by tissue from the AURA trials and patients with a confirmed T790M mutation by plasma from the placebo-chemotherapy arm of the phase III randomized IMPRESS trial. The study designs of the AURA and IMPRESS trials have been previously reported and are summarized in Table 1 [19, 25]. AURA2 was almost identical in design to the AURA extension trial 
Table 1 Summary of study designs of the AURA extension, AURA2 and IMPRESS trials [19, 25]

\begin{tabular}{|c|c|c|c|}
\hline Characteristics & AURA extension & AURA2 & IMPRESS \\
\hline $\begin{array}{l}\text { Clinical trial } \\
\text { identifier }\end{array}$ & NCT01802632 & NCT02094261 & NCT01544179 \\
\hline Study type & $\begin{array}{l}\text { Phase II, open-label, single-arm, } \\
\text { multicentre }\end{array}$ & Phase II, open-label, single-arm & $\begin{array}{l}\text { Phase III randomized, double-blind, } \\
\text { placebo-controlled, parallel, multicentre } \\
\text { study }\end{array}$ \\
\hline $\begin{array}{l}\text { T790M central } \\
\text { testing }\end{array}$ & $\begin{array}{l}\text { Performed prospectively; central } \\
\text { result (cobas }{ }^{\circledR} \text { EGFR mutation test), } \\
\text { mandatory to determine eligibility }\end{array}$ & $\begin{array}{l}\text { Performed prospectively; central result } \\
\text { (cobas }{ }^{\circledR} \text { EGFR mutation test), } \\
\text { mandatory to determine eligibility }\end{array}$ & $\begin{array}{l}\text { Performed retrospectively; central result } \\
\text { (BEAMing plasma assay) as exploratory } \\
\text { objective }\end{array}$ \\
\hline $\begin{array}{l}\text { Primary efficacy } \\
\text { objective }\end{array}$ & $\begin{array}{l}\text { ORR based on RECIST v1.1 assessed } \\
\text { by BICR }\end{array}$ & $\begin{array}{l}\text { ORR based on RECIST v1.1 assessed } \\
\text { by BICR }\end{array}$ & $\begin{array}{l}\text { PFS for continuing gefitinib plus } \\
\text { platinum-based doublet chemotherapy } \\
\text { vs. platinum-based doublet } \\
\text { chemotherapy alone }\end{array}$ \\
\hline $\begin{array}{l}\text { Secondary } \\
\text { efficacy } \\
\text { objectives }\end{array}$ & $\begin{array}{l}\text { DCR, DoR, time to first } \\
\text { documentation of objective } \\
\text { response, best change from baseline } \\
\text { in size of TL, PFS and OS }\end{array}$ & $\begin{array}{l}\text { DCR, DoR, time to first documentation } \\
\text { of objective response, best change } \\
\text { from baseline in size of TL, PFS and } \\
\text { OS }\end{array}$ & $\begin{array}{l}\text { OS, ORR and DCR for continuing } \\
\text { gefitinib plus platinum-based doublet } \\
\text { chemotherapy vs. platinum-based } \\
\text { doublet chemotherapy alone }\end{array}$ \\
\hline $\begin{array}{l}\text { Dosing and } \\
\text { patient cohorts }\end{array}$ & $\begin{array}{l}\text { Osimertinib } 80 \mathrm{mg} \text { tablet taken once } \\
\text { daily } \\
\text { Second-line patients (pre-treated with } \\
\text { one EGFR-TKI and no other } \\
\text { treatment regimens), } n=61 \\
\geq \text { Third-line patients (pre-treated } \\
\text { with at least one EGFR-TKI and } \\
\text { one other prior line of therapy), } \\
n=140\end{array}$ & $\begin{array}{l}\text { Osimertinib } 80 \mathrm{mg} \text { tablet taken once } \\
\text { daily } \\
\text { Second-line patients (pre-treated with } \\
\text { one EGFR-TKI and no other treatment } \\
\text { regimen), } n=68 \\
\geq \text { Third-line patients (pre-treated with } \\
\text { at least one EGFR-TKI and one } \\
\text { platinum-based doublet chemotherapy } \\
\text { regimen), } n=142\end{array}$ & $\begin{array}{l}\text { Control arm received standard pemetrexed } \\
\text { plus cisplastin chemotherapy (maximum } \\
\text { six cycles, intravenously on Day } 1 \text { of } \\
\text { each cycle) }\end{array}$ \\
\hline Study period & $\begin{array}{l}\text { First dose of first patient: } 14 \text { May } \\
\text { 2014; first dose of last patient: } 21 \\
\text { October } 2014\end{array}$ & $\begin{array}{l}\text { First dose of first patient: } 13 \text { June } 2014 \text {; } \\
\text { first dose of last patient: } 27 \text { October } \\
2014\end{array}$ & $\begin{array}{l}\text { First patient enrolled: } 29 \text { March 2012; last } \\
\text { patient enrolled: } 9 \text { December } 2013\end{array}$ \\
\hline Data cut-off & 1 November $2016^{\mathrm{b}}$ & 1 November $2016^{\mathrm{b}}$ & 16 November 2015 \\
\hline $\begin{array}{l}\text { Assessment of } \\
\text { tumour } \\
\text { progression } \\
\text { (RECIST }^{\text {v1.1) }}\end{array}$ & $\begin{array}{l}\text { Screening, }-28 \text { days to date of first } \\
\text { dose (day } 0 \text { ) and every } 6 \text { weeks } \\
( \pm 7 \text { days) until disease progression }\end{array}$ & $\begin{array}{l}\text { Screening, }-28 \text { days to date of first } \\
\text { dose (day } 0) \text { and every } 6 \text { weeks } \\
( \pm 7 \text { days) until disease progression }\end{array}$ & $\begin{array}{l}\text { Screening, }-4 \text { weeks to date of } \\
\text { randomization }{ }^{\mathrm{d}} \text { and every } 6 \text { weeks } \\
( \pm 7 \text { days }) \text { until disease progression }\end{array}$ \\
\hline $\begin{array}{l}\text { Treatment } \\
\text { exposure at } \\
\text { data cut-off, } \\
\text { median } \\
\text { (range) }\end{array}$ & 15.2 months $(0.1-29.7)$ & 16.9 months $(0.03-28.7)$ & $\begin{array}{l}5.5 \text { months }(0.4-27.6) \text { for the platinum- } \\
\text { based doublet chemotherapy arm } \\
\text { (control arm) }\end{array}$ \\
\hline
\end{tabular}

BICR blinded independent central review, $D C R$ disease control rate, $D o R$ duration of response, $E G F R$ epidermal growth factor receptor, $N C$ noncalculable, ORR objective response rate, $O S$ overall survival, PFS progression-free survival, RECIST response evaluation criteria in solid tumours, TKI tyrosine kinase inhibitor, $T L$ tumour lesion

${ }^{\mathrm{a}}$ A subgroup of patients in the control arm with a confirmed T790M mutation has been used as a comparator with the AURA extension and AURA2 patients; these patients received standard pemetrexed $\left(500 \mathrm{mg} / \mathrm{m}^{2}\right)$ plus cisplastin $\left(75 \mathrm{mg} / \mathrm{m}^{2}\right)$ chemotherapy (maximum six cycles, intravenously on Day 1 of each cycle)

${ }^{\mathrm{b}} \mathrm{PFS}$ and OS analyses were based on the 1 November 2016 data cut-off (DCO) from the AURA extension and AURA2 studies; ORR and DCR analyses were based on the 1 November 2015 DCO from the AURA extension and AURA2 studies

${ }^{\mathrm{c}}$ The mean time difference between most recent progression to start of treatment for pooled data of AURA extension and AURA2 was 78.20 days and was 17.05 days for the T790M mutation-positive subgroup of the chemotherapy arm of IMPRESS (Supplementary Table 1)

${ }^{\mathrm{d}}$ Baseline assessments had to be performed no more than 4 weeks before the start of treatment, and ideally as close as possible to the start of study treatment. Follow-up assessments were performed every 6 weeks after randomization (within a window of \pm 7 days of the scheduled date) until objective disease progression as defined by RECIST. At screening, eligibility was decided as quickly as possible to shorten the time from documented radiological progression to start of pemetrexed in combination with cisplatin and randomized study treatment. From Day -28 to Day 0 was preferred. Following progression, but before randomization, continuation of gefitinib was encouraged. However, if a patient stopped taking gefitinib treatment, the maximum allowed time off treatment prior to randomization was 4 weeks. All other screening assessments had to be completed within the specified 28 days 
with the studies prospectively planned to provide replication of data (Table 1). Given the similar trial designs, patients from the AURA extension and AURA2 studies were pooled to increase the precision of the estimate of the primary efficacy endpoint.

\subsection{Population}

Summaries and analyses of endpoints are based on the T790M mutation-positive patients from the pooled AURA extension and AURA2 trials and the control arm of the IMPRESS trial. In AURA extension and AURA2, T790M mutation testing was performed centrally on tumour tissue using the cobas ${ }^{\circledR}$ EGFR mutation test (Roche Molecular Systems Inc). Tumour biopsies were taken after confirmation of disease progression on the most recent treatment regimen [19]. In IMPRESS, biomarker research was performed for EGFR mutations, including T790M mutation status, using ctDNA [26]. For patients in the pooled AURA population, 405/411 treated with osimertinib $80 \mathrm{mg}$ had a confirmed T790M mutation and were included in the analysis (Table 1). For patients in the pooled AURA population who were in the second-line treatment setting, $127 / 129$ had a confirmed T790M mutation. For patients in the chemotherapy arm of the IMPRESS study, 61/132 patients had a confirmed T790M mutation by ctDNA.

As discussed in the statistical methods below, prior to analysis of endpoints, differences between baseline (i.e. pre-randomization), demographic and disease characteristics were accounted for by cohort balancing to provide the dataset for analysis of efficacy.

\subsection{Efficacy Endpoints}

Primary analysis endpoints were PFS, objective response rate (ORR, defined as the number [\%] of patients with measurable disease with at least one confirmed visit response of complete response [CR] or partial response $[P R]$ ), disease control rate (DCR, defined as the percentage of patients who have a best objective response of CR, PR or stable disease) and OS. PFS, DCR and ORR are reported based on independent central review (ICR) of radiological data. Analyses were also performed on PFS, ORR, DCR and OS for second-line patients only. PFS was defined as the time from first dose in the AURA extension and AURA2 studies and time from randomization in the IMPRESS study to the date of objective disease progression or death (by any cause in the absence of progression), regardless of whether the patient withdrew from randomized therapy or received another anti-cancer therapy prior to progression.

\subsection{Statistical Methods}

\subsubsection{Cohort Balancing}

Differences between baseline (i.e. pre-randomization), demographic and disease characteristics in the AURA and IMPRESS trials (see Supplementary Table 1) were accounted for by a three-step process of adjustment, referred to as cohort balancing (Fig. 1) [27]. The resulting adjustment is assumed to be a proxy for randomization and enables a robust comparison between osimertinib and platinum-based doublet chemotherapy using individual patient data from the AURA and IMPRESS studies, respectively.

The first step compared baseline demographic and disease characteristics with inclusion of those variables with a $p$ value $<0.2$ into estimation of propensity scores (PS) (Fig. 1). The second step involved estimation of PS. The PS for an individual is the probability of being treated with osimertinib/platinum-based doublet chemotherapy conditional on the individual's baseline variables. PS for each

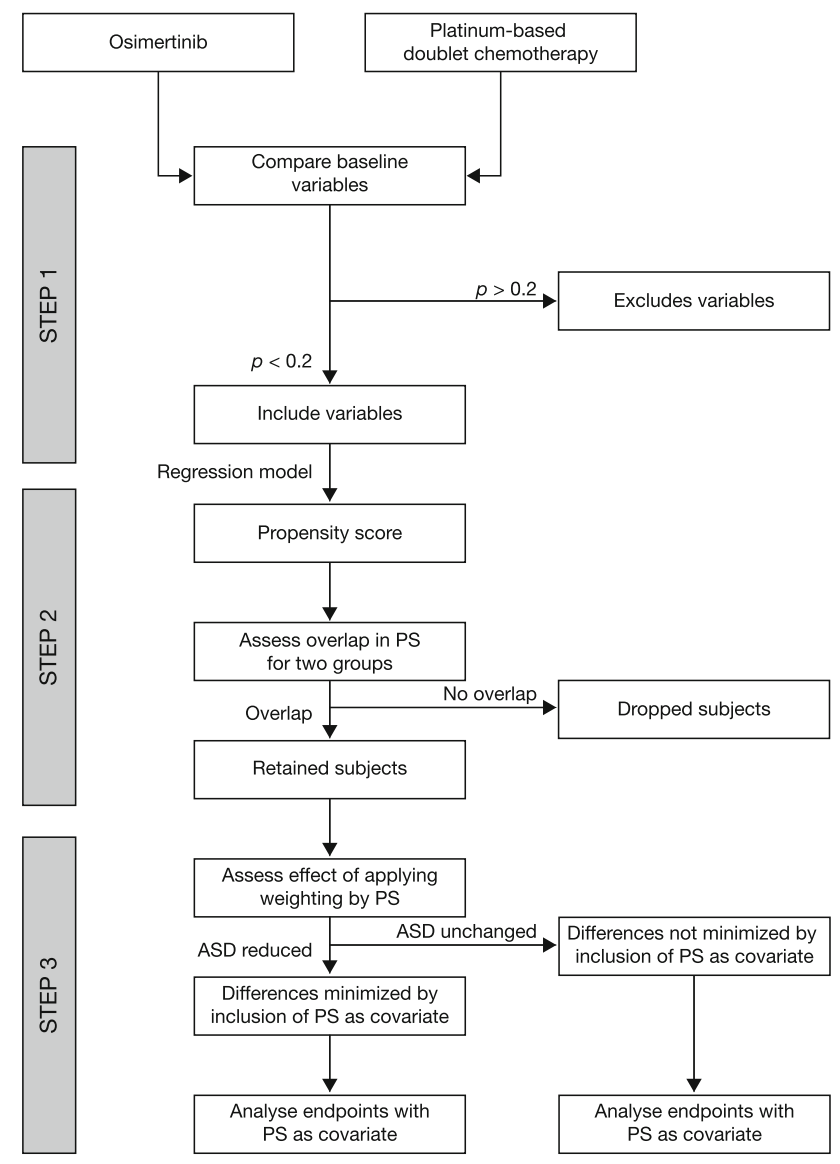

Fig. 1 Process for cohort balancing of the osimertinib and platinumbased doublet chemotherapy groups 
Table 2 Baseline demographic and disease characteristics used for generation of the regression model for estimation of propensity scores

\begin{tabular}{|c|c|c|c|c|}
\hline Variable & Osimertinib & $\begin{array}{l}\text { Platinum-based doublet } \\
\text { chemotherapy }\end{array}$ & Std diff & $p$ value $^{\mathrm{a}}$ \\
\hline Total number $(\%)$ of patients & $405(100.0)$ & $61(100.0)$ & & \\
\hline Age cont $(N)$ & 405 & 61 & 0.613 & $<0.0001$ \\
\hline Mean, SD & $\begin{array}{l}62.19 \\
(10.73)\end{array}$ & $55.77(10.20)$ & & \\
\hline Median & 63.00 & 55.00 & & \\
\hline Min, $\max$ & $\begin{array}{l}35.00, \\
89.00\end{array}$ & $38.00,79.00$ & & \\
\hline Region, $n(\%)$ & & & & $<0.0001$ \\
\hline Asia & $209(51.6)$ & $48(78.7)$ & -0.593 & \\
\hline Rest of world & $196(48.4)$ & $13(21.3)$ & 0.593 & \\
\hline Ethnicity, $n(\%)$ & & & & 0.0016 \\
\hline Asian & $240(59.3)$ & $49(80.3)$ & -0.471 & \\
\hline Other & $165(40.7)$ & $12(19.7)$ & 0.471 & \\
\hline Baseline target lesion size imputed $(N)$ & 405 & 61 & 0.335 & 0.1381 \\
\hline Mean, SD & $\begin{array}{l}60.43 \\
(38.31)\end{array}$ & $49.66(24.44)$ & & \\
\hline Median & 52.00 & 54.00 & & \\
\hline Min, $\max$ & $\begin{array}{l}10.40 \\
229.40\end{array}$ & $12.70,121.80$ & & \\
\hline $\begin{array}{l}\text { Smoking pack year history }[0=\text { never, } 1=\text { ever with pack years }<30 \text {, } \\
2=\text { ever with pack years } \geq 30], n(\%)\end{array}$ & & & & 0.0966 \\
\hline 0 & $290(71.6)$ & $40(65.6)$ & 0.130 & \\
\hline 1 & $83(20.5)$ & $11(18.0)$ & 0.062 & \\
\hline 2 & $32(7.9)$ & $10(16.4)$ & -0.262 & \\
\hline \multicolumn{5}{|l|}{ Site of disease at baseline } \\
\hline Respiratory, $n(\%)$ & $280(69.1)$ & $19(31.1)$ & 0.821 & $<0.0001$ \\
\hline Hepatic (including gall bladder), $n(\%)$ & $119(29.4)$ & $10(16.4)$ & 0.313 & 0.0345 \\
\hline Pericardial effusion, $n(\%)$ & $15(3.7)$ & $8(13.1)$ & -0.344 & 0.0016 \\
\hline Prior radiotherapy, $n(\%)$ & $198(48.9)$ & $17(27.9)$ & 0.443 & 0.0021 \\
\hline TNM classification—distant metastases, $n(\%)$ & $307(75.8)$ & $56(91.8)$ & -0.445 & 0.0050 \\
\hline TNM classification-regional lymph nodes $\mathrm{N} 3, n(\%)$ & $103(25.4)$ & $27(44.3)$ & -0.403 & 0.0022 \\
\hline
\end{tabular}

Std diff standardised mean difference refers to the mean divided by the standard deviation used to measure effect size for selection of variables ${ }^{a}$ For categorical variables, $p$ values were based on the Chi-square test or Fisher's exact test (50\% or more of the cells have expected counts of less than 5). For continuous variables, $p$ values were based on the $t$ test, or on the Wilcoxon rank-sum test if normality assumption was violated (Shapiro-Wilk test)

patient was estimated using logistic regression modelling (Fig. 1). The overlap between cohorts on estimated PS was assessed and only patients within the PS distributions of both treatment groups were included in the final analyses; a process termed 'trimming' [28]. The overlap was identified as all values between the minimum of the PS in patients treated with osimertinib and the maximum of the PS in patients treated with platinum-based doublet chemotherapy. In the final step, PS was incorporated as a covariate for analysis of the treatment comparison of osimertinib versus platinum-based doublet chemotherapy for each endpoint to adjust for remaining differences between groups (Fig. 1).

\subsubsection{Analysis of Treatment Effects}

All analyses were performed using the dataset produced by cohort balancing as described above. Summaries and analyses for ORR and DCR were based on the evaluablefor-response subset, defined as all patients who received at least one dose of treatment and had measurable disease at baseline according to the ICR or baseline imaging data. Analysis of ORR and DCR for osimertinib relative to platinum-based doublet chemotherapy was performed using a logistic regression model containing treatment as a factor and the propensity score as a covariate. PFS and OS 
Table 3 Baseline demographics and disease characteristics for total patients and those patients receiving second-line treatment only with osimertinib or platinum-based doublet chemotherapy following cohort balancing

\begin{tabular}{|c|c|c|c|c|c|c|}
\hline \multirow[t]{2}{*}{ Variable } & \multicolumn{3}{|c|}{ Total trimmed dataset } & \multicolumn{3}{|c|}{$\begin{array}{l}\text { Trimmed dataset receiving second-line treatment } \\
\text { only }\end{array}$} \\
\hline & $\begin{array}{l}\text { Osimertinib, } \\
n=288\end{array}$ & $\begin{array}{l}\text { Platinum-based doublet } \\
\text { chemotherapy, } n=53\end{array}$ & $p$ value $^{\mathrm{a}}$ & $\begin{array}{l}\text { Osimertinib, } \\
n=92\end{array}$ & $\begin{array}{l}\text { Platinum-based doublet } \\
\text { chemotherapy, } n=53\end{array}$ & $p$ value $^{\mathrm{a}}$ \\
\hline Sex, $n(\%)$ & & & 0.5341 & & & 0.7210 \\
\hline Male & $96(33.3)$ & $30(37.7)$ & & $32(34.8)$ & $20(37.7)$ & \\
\hline Female & $192(66.7)$ & $33(62.3)$ & & $60(65.2)$ & $33(62.3)$ & \\
\hline Age, years & & & 0.0156 & & & 0.0082 \\
\hline Mean, SD & $60.6(10.7)$ & $56.7(10.3)$ & & $61.8(11.3)$ & $56.7(10.3)$ & \\
\hline Median & 60.5 & 56.0 & & 60.0 & 56.0 & \\
\hline Range & $35.0-89.0$ & $38.0-79.0$ & & $36.0-89.0$ & $38.0-79.0$ & \\
\hline Region, $n(\%)$ & & & 0.0018 & & & $<0.0001$ \\
\hline Asia & $175(60.8)$ & $40(75.5)$ & & $48(52.2)$ & $40(75.5)$ & \\
\hline Europe & $48(16.7)$ & $13(24.5)$ & & $14(15.2)$ & $13(24.5)$ & \\
\hline North America & $60(20.8)$ & $0(0.0)$ & & $27(29.3)$ & $0(0.0)$ & \\
\hline Rest of the world & $5(1.7)$ & $0(0.0)$ & & $3(3.3)$ & $0(0.0)$ & \\
\hline Ethnicity, $n(\%)$ & & & 0.4513 & & & 0.1380 \\
\hline Asian & $193(67.0)$ & $40(75.5)$ & & $55(59.8)$ & $40(75.5)$ & \\
\hline Non-Asian & $94(32.6)$ & $13(24.5)$ & & $36(39.1)$ & $13(24.5)$ & \\
\hline Not applicable & $1(0.3)$ & $0(0.0)$ & & $1(1.1)$ & $0(0.0)$ & \\
\hline $\begin{array}{l}\text { Time, from recent progression to } \\
\text { start of treatment, days }\end{array}$ & & & $<0.0001$ & & & $<0.0001$ \\
\hline Mean (SD) & $74.1(58.2)$ & $16.9(6.6)$ & & $75.7(61.2)$ & $16.9(6.6)$ & \\
\hline $\begin{array}{l}\text { Number of previous EGFR-TKIs, } \\
\text { including re-challenge, } n(\%)\end{array}$ & & & $<0.0001$ & & & \\
\hline 1 & $169(58.7)$ & $53(100.0)$ & & $92(100.0)$ & $53(100.0)$ & \\
\hline 2 & $66(22.9)$ & $0(0.0)$ & & $0(0.0)$ & $0(0.0)$ & \\
\hline 3 & $33(11.5)$ & $0(0.0)$ & & $0(0.0)$ & $0(0.0)$ & \\
\hline 4 & $12(4.2)$ & $0(0.0)$ & & $0(0.0)$ & $0(0.0)$ & \\
\hline 5 & $4(1.4)$ & $0(0.0)$ & & $0(0.0)$ & $0(0.0)$ & \\
\hline$>5$ & $4(1.4)$ & $0(0.0)$ & & $0(0.0)$ & $0(0.0)$ & \\
\hline $\begin{array}{l}\text { Previous platinum-based doublet } \\
\text { therapy, } n(\%)\end{array}$ & $182(63.2)$ & $0(0.0)$ & $<0.0001$ & $0(0.0)$ & $0(0.0)$ & \\
\hline $\begin{array}{l}\text { Previous platinum-based doublet } \\
\text { plus bevacizumab therapy, } n(\%)\end{array}$ & $37(12.8)$ & $0(0.0)$ & 0.0057 & $0(0.0)$ & $0(0.0)$ & \\
\hline Baseline target lesion size, $\mathrm{mm}$ & & & 0.8882 & & & 0.6568 \\
\hline Mean (SD) & $51.5(28.1)$ & $50.0(23.0)$ & & $50.9(28.6)$ & $50.0(23.0)$ & \\
\hline \multicolumn{7}{|l|}{ Site of disease at baseline, $n(\%)$} \\
\hline Brain/central nervous system & $99(34.4)$ & $17(32.1)$ & 0.7454 & $22(23.9)$ & $17(32.1)$ & 0.2858 \\
\hline Pleural effusion & $105(36.5)$ & $20(37.7)$ & 0.8592 & $35(38.0)$ & $20(37.7)$ & 0.9707 \\
\hline Respiratory & $174(60.4)$ & $19(35.8)$ & 0.0009 & $47(51.1)$ & $19(35.8)$ & 0.0760 \\
\hline Hepatic (including gall bladder) & $62(21.5)$ & $10(18.9)$ & 0.6628 & $17(18.5)$ & $10(18.9)$ & 0.9537 \\
\hline Skin/soft tissue & $12(4.2)$ & $2(3.8)$ & 0.8946 & $2(2.2)$ & $2(3.8)$ & 0.6233 \\
\hline Bone and locomotor & $128(44.4)$ & $27(50.9)$ & 0.3825 & $38(41.3)$ & $27(50.9)$ & 0.2610 \\
\hline Lymph nodes & $137(47.6)$ & $26(49.1)$ & 0.8421 & $40(43.5)$ & $26(49.1)$ & 0.5160 \\
\hline Pericardial effusion & $13(4.5)$ & $4(7.5)$ & 0.3511 & $3(3.3)$ & $4(7.5)$ & 0.2591 \\
\hline
\end{tabular}


Table 3 continued

\begin{tabular}{|c|c|c|c|c|c|c|}
\hline \multirow[t]{2}{*}{ Variable } & \multicolumn{3}{|c|}{ Total trimmed dataset } & \multicolumn{3}{|c|}{$\begin{array}{l}\text { Trimmed dataset receiving second-line treatment } \\
\text { only }\end{array}$} \\
\hline & $\begin{array}{l}\text { Osimertinib, } \\
n=288\end{array}$ & $\begin{array}{l}\text { Platinum-based doublet } \\
\text { chemotherapy, } n=53\end{array}$ & $\overline{p \text { value }^{\mathrm{a}}}$ & $\begin{array}{l}\text { Osimertinib, } \\
n=92\end{array}$ & $\begin{array}{l}\text { Platinum-based doublet } \\
\text { chemotherapy, } n=53\end{array}$ & $\overline{p \text { value }^{\mathrm{a}}}$ \\
\hline Other & $63(21.9)$ & $10(18.9)$ & 0.6238 & 18 (19.6) & $10(18.9)$ & 0.9184 \\
\hline
\end{tabular}

$E G F R-T K I$ epidermal growth factor receptor-tyrosine kinase inhibitor, $S D$ standard deviation

${ }^{a}$ For categorical variables, $p$ values were based on the Chi-square test or Fisher's exact test (50\% or more of the cells have expected counts of less than 5). For continuous variables, $p$ values were based on $t$ test, or on the Wilcoxon rank-sum test if normality assumption was violated (ShapiroWilk test)

were analysed using a Cox proportional hazards model with treatment as a factor and the estimated PS as a covariate. Kaplan-Meier PFS and OS curves for osimertinib and platinum-based doublet chemotherapy were generated.

Differences in baseline variables were compared by statistical tests. For categorical variables, $p$ values were based on the Chi-square test or Fisher's exact test. For categorical variables with more than two levels, an overall $p$ value was calculated (instead of calculating $p$ values for each level of the variable).

The effect of trimming (i.e. removal of patients for which the value of the calculated PS was not within the overlapping region between the two study groups) was evaluated for the endpoints PFS, ORR, DCR and OS. Sensitivity analyses were performed on the T790M+adj untrimmed set to evaluate the effect of removing subjects to produce the trimmed dataset.

\section{Results}

The results used to identify the variables for inclusion in the PS model are provided in Table 2. A full list of variables assessed for inclusion is provided in Supplementary Table 1. Twenty-two initial variables were identified, including a larger mean tumour size in the AURA trials (Supplementary Table 1). Variables with $p<0.2$ were included in the PS model. Following cohort balancing, $288 / 405$ patients were retained in the osimertinib group and $53 / 61$ patients were retained in the platinum-based doublet chemotherapy group; of these, 92 and 53 patients, respectively, received osimertinib or platinum-based doublet chemotherapy as second-line therapy. Baseline demographics and disease characteristics for these populations are shown in Table 3.

Patients in the osimertinib group were older relative to the platinum-based doublet chemotherapy group (mean age 60.6 vs. 56.7 years, $p=0.0156$ ) (Table 3). The mean time from recent progression to start of treatment was longer for the osimertinib group compared with the platinum-based doublet chemotherapy group (74.1 vs. 16.9 days, $p<0.001)$, reflecting the difference in trial design whereby patients in the IMPRESS study were randomized within 4 weeks of disease progression following first-line treatment. Significantly more patients received previous platinum-based doublet chemotherapy and previous platinumbased doublet chemotherapy plus bevacizumab therapy in the osimertinib group compared with the platinum-based doublet chemotherapy group due to the differences in design of the IMPRESS and AURA trials. Similar differences in age and mean time from recent progression to start of treatment were observed for patients who received osimertinib or platinum-based doublet chemotherapy as second-line treatment (Table 3).

\subsection{Progression-Free Survival}

Median PFS of osimertinib and platinum-based doublet chemotherapy was 10.9 and 5.3 months, respectively (HR 0.278, 95\% CI 0.188-0.409, $p<0.0001$ ) (Fig. 2a).

A statistically significant improvement in median PFS was also observed for the osimertinib group compared with the platinum-based doublet chemotherapy group for the subset of patients treated with osimertinib $(n=92)$ or platinum-based doublet chemotherapy $(n=53)$ as secondline treatment (HR $0.251,95 \%$ CI $0.155-0.405, p<0.0001$; median 9.7 vs. 5.3 months) (Fig. 2b).

\subsection{PFS Sensitivity Analysis: Untrimmed Data Set}

Use of the untrimmed data set and the PS as a covariate for all patients with $\mathrm{T} 790 \mathrm{M}+$ status demonstrated a statistically significant improvement for the osimertinib group relative to the platinum-based doublet chemotherapy group of 10.9 months and 5.3 months, respectively (HR 0.283, 95\% CI 0.194-0.412, $p<0.0001)$. Similarly, using the untrimmed dataset and PS as a covariate for T790M+ patients receiving second-line treatment demonstrated a statistically significant improvement for the osimertinib group 
Fig. 2 Kaplan-Meier plot of progression-free survival by independent central review a for all patients following cohort balancing: $n=288$ receiving osimertinib; $n=53$ receiving platinum-based doublet chemotherapy; $\mathbf{b}$ for subset of patients receiving osimertinib $(n=92)$ or platinum-based doublet chemotherapy $(n=53)$ as a second-line treatment
A

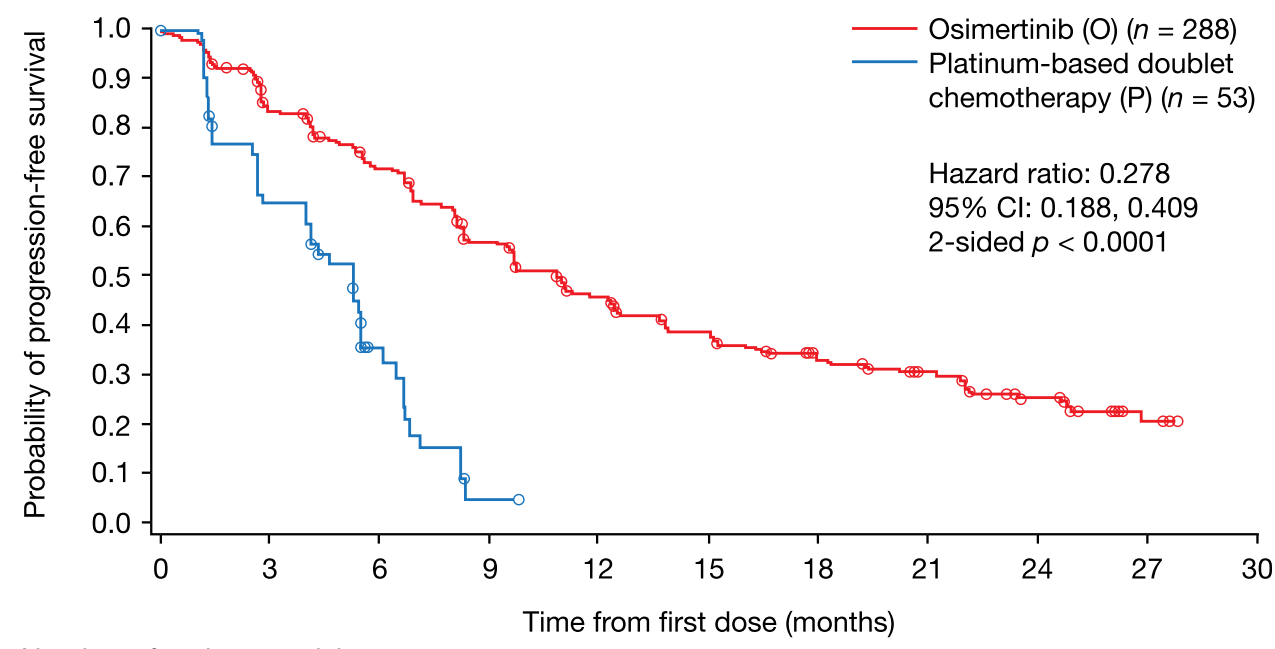

Number of patients at risk

$\begin{array}{lccccccccccc}\mathrm{O} & 288 & 234 & 196 & 147 & 112 & 89 & 67 & 57 & 39 & 10 & 0 \\ \mathrm{P} & 53 & 32 & 12 & 1 & 0 & 0 & 0 & 0 & 0 & 0 & 0\end{array}$

\section{B}

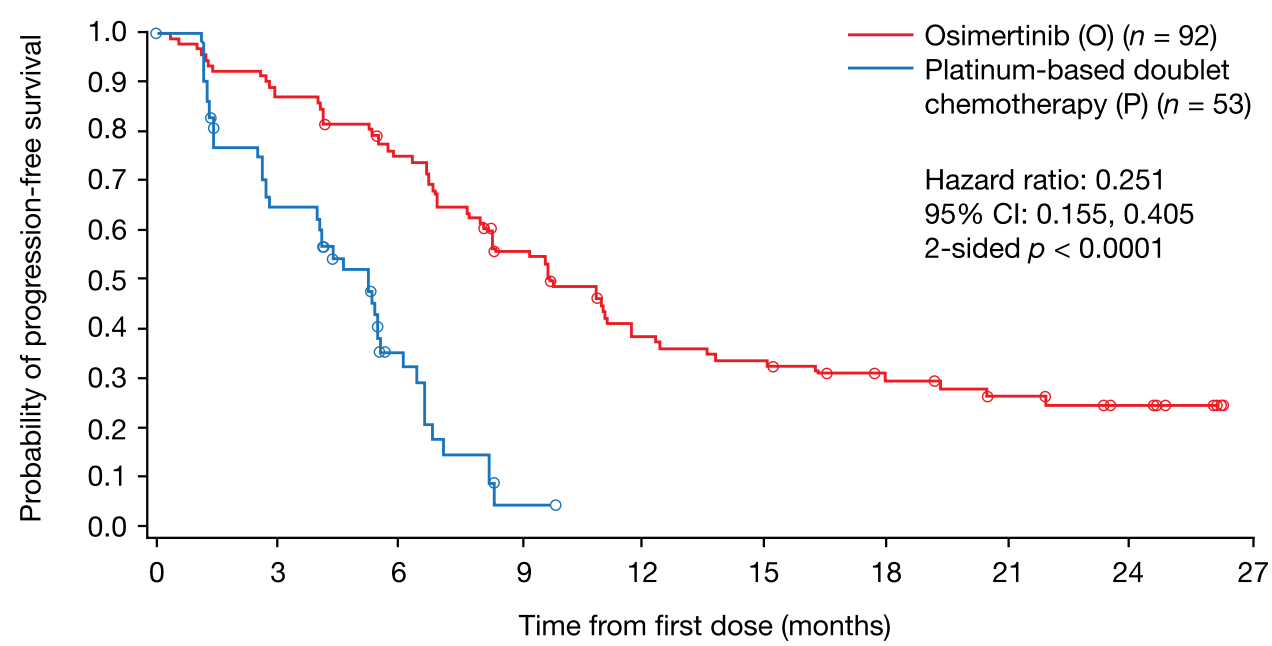

Number of patients at risk

$\begin{array}{lllllllllll}\mathrm{O} & 92 & 80 & 67 & 47 & 31 & 27 & 19 & 15 & 11 & 0 \\ \mathrm{P} & 53 & 32 & 12 & 1 & 0 & 0 & 0 & 0 & 0 & 0\end{array}$

Circle indicates censored observation. relative to the platinum-based doublet chemotherapy group of 9.8 months and 5.3 months respectively (HR 0.250, 95\% CI $0.157-0.397, p<0.0001)$. These results are consistent with those produced using the trimmed data set.

The improvement for osimertinib was similar to the unadjusted comparison with the platinum-based doublet chemotherapy group (HR $0.28,95 \%$ CI $0.19-0.41$, $p<0.001)$.

\subsection{Objective Response Rate and Disease Control Rate}

ORR and DCR were assessed in the evaluable-for-response subset ( $n=277$ osimertinib; $n=48$ platinum-based doublet chemotherapy). The ORR was $64.3 \%$ (178/277) in the osimertinib treatment group compared with $33.3 \%(16 / 48)$ in the platinum-based doublet chemotherapy group (OR 
Fig. 3 Kaplan-Meier plot of overall survival by independent central review a for all patients following cohort balancing: $n=288$ receiving osimertinib; $n=53$ receiving platinumbased doublet chemotherapy, b for subset of patients receiving osimertinib $(n=92)$ or platinum-based doublet chemotherapy $(n=53)$ as a second-line treatment

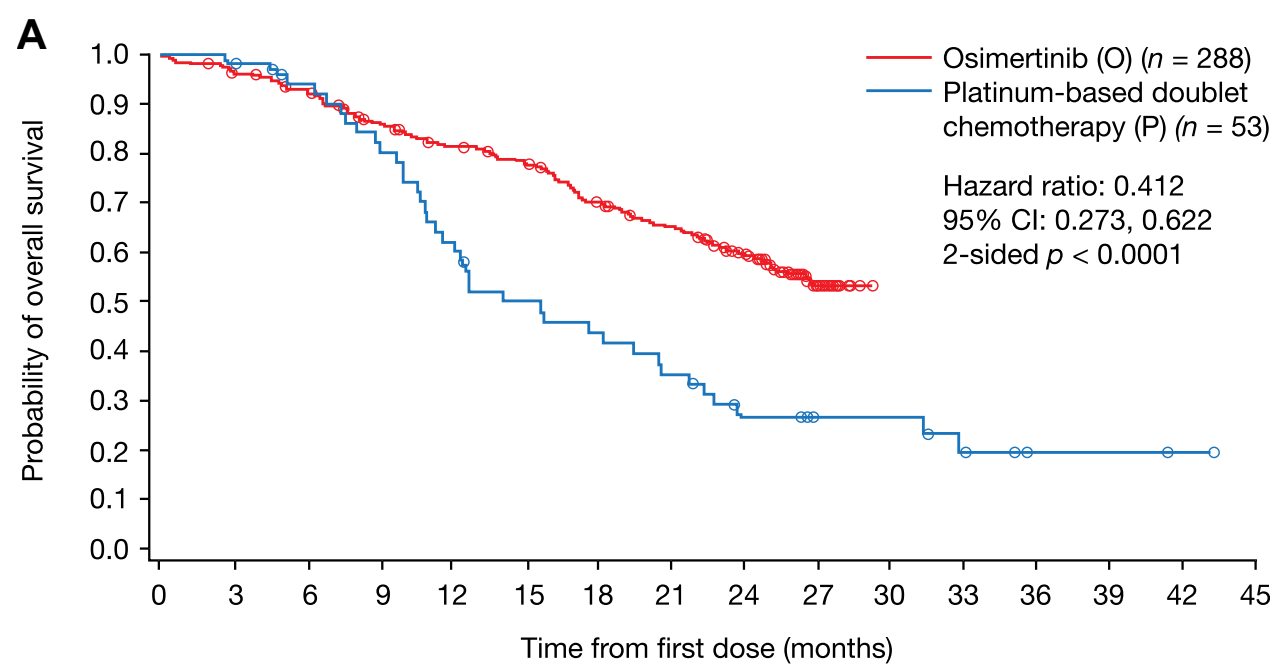

Number of patients at risk

$\begin{array}{lcccccccccccccccc}\mathrm{O} & 288 & 276 & 264 & 240 & 223 & 212 & 188 & 172 & 146 & 41 & 0 & 0 & 0 & 0 & 0 & 0 \\ \mathrm{P} & 53 & 52 & 47 & 41 & 31 & 24 & 21 & 17 & 11 & 8 & 8 & 5 & 2 & 2 & 1 & 0\end{array}$

B

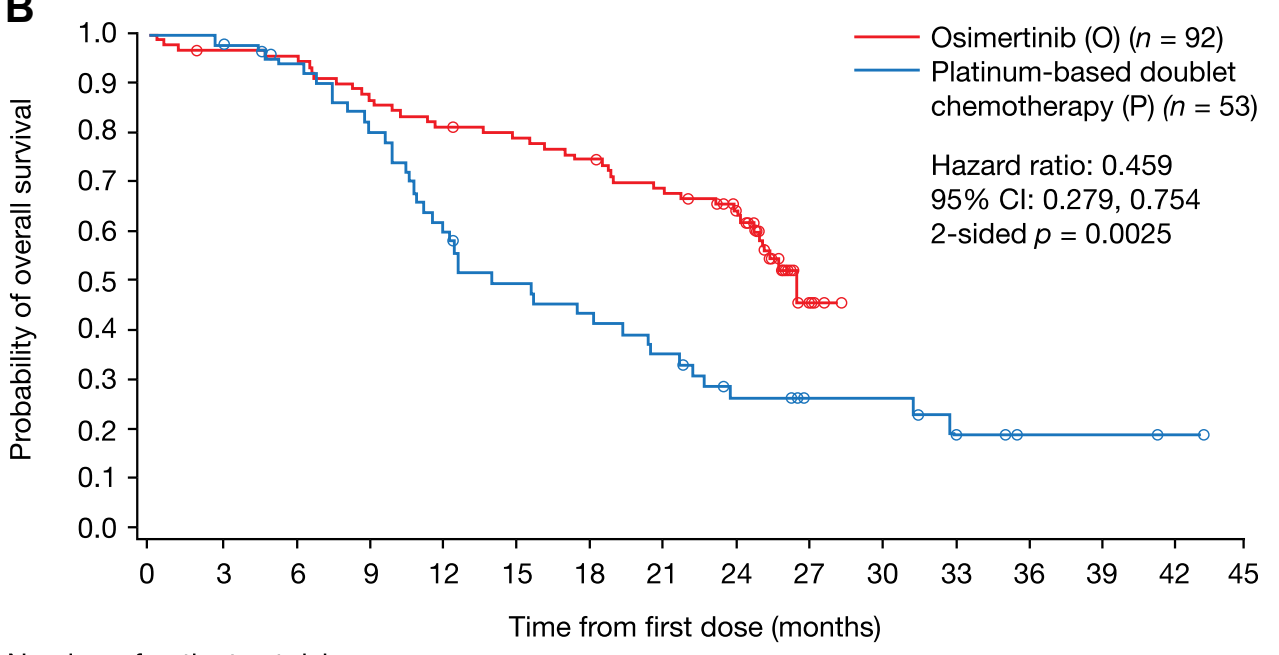

Number of patients at risk

$\begin{array}{lllllllllllllllll}\mathrm{O} & 92 & 88 & 87 & 80 & 74 & 71 & 67 & 61 & 54 & 6 & 0 & 0 & 0 & 0 & 0 & 0 \\ \mathrm{P} & 53 & 52 & 47 & 41 & 31 & 24 & 21 & 17 & 11 & 8 & 8 & 5 & 2 & 2 & 1 & 0\end{array}$

Circle indicates censored observation.
5.31, 95\% CI 2.47-11.40, $p<0.001)$. The DCR also demonstrated a statistically significant improvement in the osimertinib treatment group compared with the platinumbased doublet chemotherapy group; 92.1 versus $75.0 \%$, respectively (OR 4.72, 95\% CI 1.92-11.58, $p<0.001$ ).

For patients treated with osimertinib or platinum-based doublet chemotherapy as second-line treatment $(n=89$ osimertinib; $n=48$ platinum-based doublet chemotherapy), a statistically significant improvement in ORR and DCR was also observed for the osimertinib group compared with the platinum-based doublet chemotherapy group (ORR: 67.4 vs. $33.3 \%$, OR 5.63, 95\% CI 2.32-13.67, $p<0.001$; DCR: 93.3 vs. $75.0 \%$, OR $5.73,95 \%$ CI $1.84-17.88, p=0.003)$.

\subsection{Overall Survival}

At the data cut-off for OS (pooled AURA dataset: 1 November 2016; platinum-based doublet chemotherapy group: 16 November 2015), median OS time for the 
osimertinib group was not calculable for the pooled AURA dataset and the median OS time for the platinum-based doublet chemotherapy group was 14.1 months. The HR for OS for osimertinib relative to platinum-based doublet chemotherapy was $0.412 \quad(95 \%$ CI $0.273-0.622$, $p=0.0001$ ) (Fig. 3a).

For patients who received osimertinib or platinum-based doublet chemotherapy as second-line treatment, at the data cut-off for OS, median OS time for the osimertinib group was 26.5 months and the median OS time for the platinumbased doublet chemotherapy group was 14.1 months. The HR for OS for osimertinib relative to platinum-based doublet chemotherapy was 0.459 (95\% CI $0.279-0.754$, $p=0.0025$ ) (Fig. 3b).

\subsection{Overall Survival: Censored at Longest Follow- up for Osimertinib}

To account for potential differences in follow-up time between the AURA extension/AURA2 and IMPRESS studies, a sensitivity analysis was conducted, in which patients in the IMPRESS study were censored at the point of longest follow-up in the AURA extension/AURA2 studies. The median OS time for the osimertinib group was not calculable, which was consistent with the pooled analysis for AURA extension and AURA2 data. Median OS time for the platinum-based doublet chemotherapy group was 14.1 months. The HR for OS for osimertinib relative to platinum-based doublet chemotherapy was 0.413 (95\% CI 0.273-0.623, $p=0.0001$ ) (Fig. 4).

\section{Discussion}

Prior to the approval of osimertinib, approaches to address patients with EGFR T790M mutation-positive NSCLC, the most common cause of acquired drug resistance in EGFRm NSCLC, have been limited by a lack of efficacy and doselimiting toxicity $[9-18,29-35]$. Osimertinib recently received regulatory approvals in North America, Europe and Asia as the first indicated treatment for patients with metastatic EGFR T790M mutation-positive NSCLC $[20,21,36,37]$. Approval was based on evidence from the AURA extension and AURA2 phase II single-arm trials [19]. Prior to publication of randomized, comparative control data for osimertinib, across different endpoints, from the AURA 3 trial, we performed an adjusted indirect comparison of osimertinib with platinum-based doublet chemotherapy.

The approach allows the comparison of treatment results with platinum-based doublet chemotherapy when only single-arm trial results are available, thereby offering a bridging methodology until phase III confirmatory trial data are available. The approach continues to have utility when phase III trial data are available, as patients switching to trial treatment is becoming more frequent in randomized oncology trials, resulting in confounding of post-switch endpoints, such as OS. Confounding makes determination of OS impact more challenging. It is anticipated that AURA3 may not provide a true measure of OS benefit due to a high proportion (60\%) of patients switching to osimertinib from the comparator treatment [24]. Therefore,
Fig. 4 Kaplan-Meier plot of overall survival censored at point on longest follow-up for osimertinib (T790M+adj set) for all patients following cohort balancing: $n=288$ receiving osimertinib; $n=53$ receiving platinum-based doublet chemotherapy

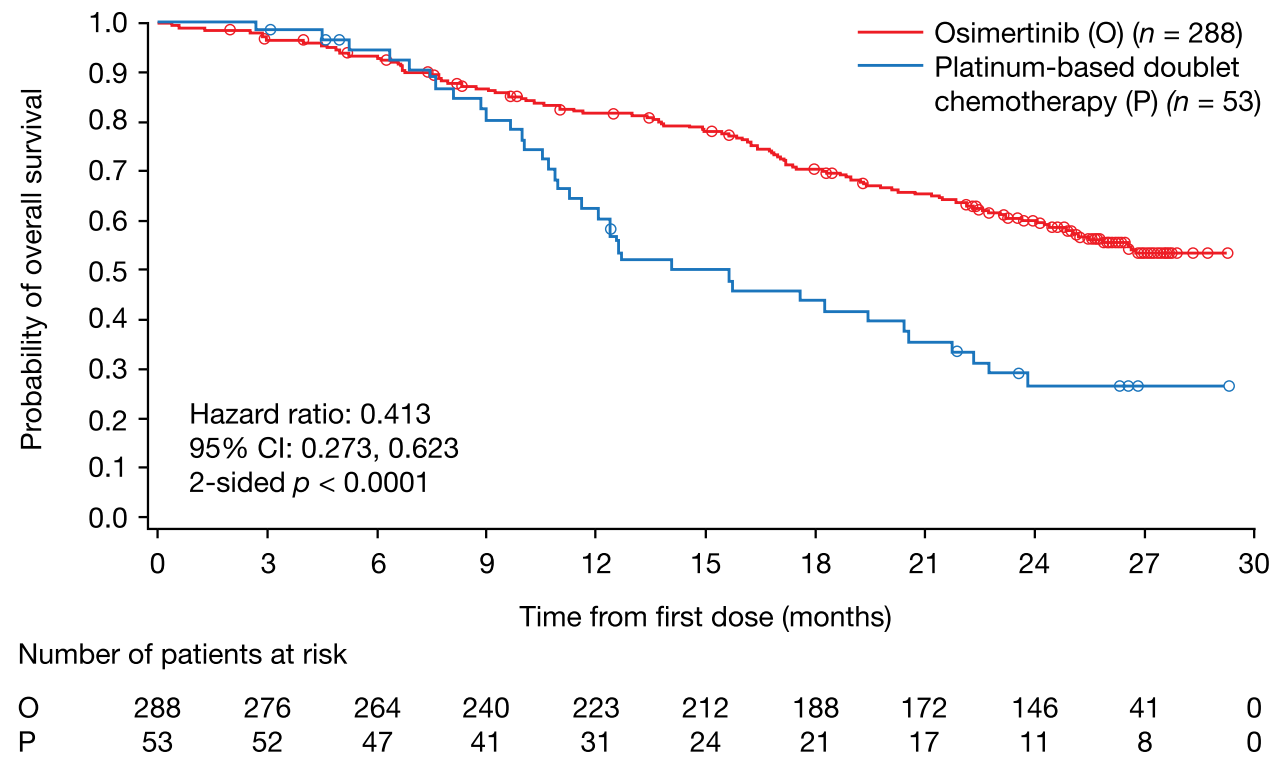

Circle indicates censored observation. 
data from these types of indirect comparison studies may provide the best available survival estimate. Additionally, they may help inform appropriate statistical methods that can adjust for the impact of treatment switching.

Our study used PS analyses to adjust for imbalances in demographics and clinical characteristics. It should be noted that although PS can balance observed baseline covariates between exposure groups, it cannot balance unmeasured characteristics and confounders. Hence, as with all observational studies, and unlike blinded randomized controlled trials, PS analyses have the limitation that unobserved differences between the two groups will more likely confound analysis of efficacy. However, the large effect size observed in our study suggests that a comparative benefit would remain despite the possibility of unmeasured confounders. In addition, approaches using the PS do not overcome initial selection bias. For example, time from recent (radiological) disease progression to start of treatment differed between the IMPRESS and AURA trials. Whereas all patients in the platinum-based doublet chemotherapy group started treatment within 29 days of previous documented disease progression, only 25/405 patients in the osimertinib group started treatment within this period. This variable was excluded from the list of candidate variables as adjustment was not feasible. However, non-inclusion of this variable seems acceptable as the delayed start of treatment for osimertinib is most likely a disadvantage for the osimertinib group (i.e. results from analysis of efficacy would be a conservative estimate of the benefit of osimertinib).

Sensitivity analyses using the untrimmed dataset and PS as a covariate for patients with $\mathrm{T} 790 \mathrm{M}+$ status produced results consistent with those produced using both the trimmed data set and the unadjusted platinum-based doublet chemotherapy group.
T790M mutation was determined using different methodologies in the two studies: tissue biopsy in AURA and plasma ctDNA in IMPRESS. Tissue biopsy was not available for IMPRESS for comparison. Of the different testing methodologies, tissue biopsy is regarded as the gold standard. In a retrospective assessment of plasma genotyping in patients with advanced NSCLC who were treated with osimertinib, similar efficacy outcomes were reported in patients with T790M-positive plasma samples (ORR, 63\%; median PFS, 9.7 months) compared with patients with T790M-positive tumour samples (ORR, 62\%; median PFS, 9.7 months) [38]. These data suggest that the use of plasma versus tissue testing is unlikely to impact on the efficacy outcomes with platinum-based doublet chemotherapy, which is an untargeted treatment, and further suggest that a positive plasma test is a reliable way to select patients for osimertinib treatment [38]. In addition, there is greater than $90 \%$ concordance across two platforms (cobas ${ }^{\circledR}$ and BEAMing) used for T790M mutation detection [39].

Taking the limitations highlighted above into consideration, the findings of this indirect comparison demonstrated a statistically significant and clinically meaningful improvement in PFS, ORR and DCR for osimertinib relative to platinum-based doublet chemotherapy. The median PFS for osimertinib and for platinum-based doublet chemotherapy reported in our study (10.9 and 5.3 months, respectively) were consistent with previously reported PFS for osimertinib-treated EGFR T790M mutation-positive patients in the AURA extension trial (9.6 months) [19] and the control arm of the IMPRESS trial (5.4 months) [25].

This indirect comparison reported a statistically significant OS benefit in favour of the osimertinib group. However, as data for OS were immature for the osimertinib group, median OS for osimertinib had not been reached at

Table 4 Summary of results of outcomes from indirect analysis and comparison with results from AURA3 randomized control trial

\begin{tabular}{|c|c|c|c|c|}
\hline & $\mathrm{ORR}^{\mathrm{a}}$ & $\mathrm{DCR}^{\mathrm{a}}$ & $\mathrm{PFS}^{\mathrm{b}}$ & $\mathrm{OS}^{\mathrm{b}}$ \\
\hline $\begin{array}{l}\text { Indirect } \\
\text { comparison, } \\
2 \mathrm{~L} \text { and } \geq 3 \mathrm{~L}\end{array}$ & $\begin{array}{l}64.3 \text { vs. } 33.3 \% \\
\text { OR }=5.31,95 \% \text { CI } \\
2.47-11.40, p<0.001\end{array}$ & $\begin{array}{l}92.1 \text { vs. } 75.0 \% \\
\text { OR }=4.72,95 \% \text { CI } \\
1.92-11.58, p<0.001\end{array}$ & $\begin{array}{l}\text { Median } 10.9 \text { vs. } 5.3 \text { months; } \\
\text { HR }=0.278,95 \% \text { CI } \\
0.188-0.409, p<0.0001\end{array}$ & $\begin{array}{l}\text { Median NC vs. } 14.1 \text { months; } \\
\text { HR }=0.412,95 \% \text { CI } \\
0.273-0.622, p<0.0001\end{array}$ \\
\hline $\begin{array}{l}\text { Indirect } \\
\text { comparison, } \\
\text { 2L only }\end{array}$ & $\begin{array}{l}67.4 \text { vs. } 33.3 \% \\
\text { OR }=5.63,95 \% \text { CI } \\
2.32-13.67, p<0.001\end{array}$ & $\begin{array}{l}93.3 \text { vs. } 75.0 \% \\
\text { OR }=5.73,95 \% \text { CI } \\
1.84-17.88, p=0.003\end{array}$ & $\begin{array}{l}\text { Median } 9.7 \text { vs. } 5.3 \text { months; } \\
\text { HR }=0.251,95 \% \text { CI } \\
0.155-0.405, p<0.0001\end{array}$ & $\begin{array}{l}\text { Median } 26.5 \text { vs. } 14.1 \text { months; } \\
\text { HR }=0.459,95 \% \text { CI } \\
0.279-0.754, p=0.0025)\end{array}$ \\
\hline AURA3 [24] & $\begin{array}{l}71 \text { vs. } 31 \% ; \mathrm{OR}=5.39 \\
95 \% \text { CI } 3.47-8.48 \\
p<0.001\end{array}$ & $\begin{array}{l}93 \% \text { vs. } 74 \% \\
\text { OR }=4.76,95 \% \text { CI } \\
2.64-8.84, p<0.001\end{array}$ & $\begin{array}{l}\text { Median, } 10.1 \text { vs. } 4.4 \text { months; } \\
\mathrm{HR}=0.30,95 \% \text { CI } 0.23-0.41 \\
p<0.001\end{array}$ & $\begin{array}{l}\text { Data for the OS analysis were not } \\
\text { complete at the time of this } \\
\text { report }\end{array}$ \\
\hline
\end{tabular}

$D C R$ disease control rate, $H R$ hazard ratio, $N C$ not calculable, $O R$ odds ratio, $O R R$ objective response rate, $O S$ overall survival, $P F S$ progressionfree survival

${ }^{\mathrm{a}}$ The OR analysis was performed using logistic regression model with treatment as a factor and PS as a covariate. OR $>1$ favours osimertinib. $\%$ stated for osimertinib versus chemotherapy

${ }^{\mathrm{b}}$ Analysis of PFS was performed using a Cox proportional hazards model with treatment as a factor and PS as a covariate. HR $<1$ favours osimertinib. Median stated for osimertinib versus chemotherapy 
the time of the data cut-off. It should be noted that the AURA trials are both ongoing open-label studies; the OS data used in this analysis were from the most recent data cut-off (AURA extension and AURA2, 1 November 2016) and further updates may be anticipated.

Randomized data from the phase III AURA3 trial, which evaluated osimertinib compared with platinum-based therapy plus pemetrexed in patients with EGFR T790M mutation-positive NSCLC, have now been published $[23,24]$. Consistent with the findings from our indirect comparison, in AURA3, osimertinib treatment led to significant improvements in PFS (HR 0.30, 95\% CI 0.23-0.41, $p<0.001$; median PFS 10.1 vs. 4.4 months) and ORR (71 vs. $31 \%$; OR $5.39,95 \%$ CI $3.47-8.48, p<0.001)$ when compared with platinum-based therapy plus pemetrexed (Table 4) [23, 24].

The absence of adjustment for differences due to confounding of unmeasured patient characteristics is a limitation of any indirect comparison. However, the acceptable level of consistency of the results of the indirect comparison and AURA3 provide evidence that the indirect approach is valid, particularly for estimation of OS where analysis of the RCT is heavily confounded due to treatment switching from the chemotherapy arm to osimertinib [24].

\section{Conclusions}

In summary, our findings suggest that osimertinib may be a more effective treatment than platinum-based doublet chemotherapy in patients with metastatic EGFRm T790M mutation-positive NSCLC who have progressed after EGFR-TKI, improving ORR, DCR, and PFS consistent with phase III data from AURA3 [23, 24]. In addition, the analysis of OS bridges the available evidence for the improved survival with osimertinib from AURA3, which is heavily confounded due to treatment switching.

\section{Compliance with Ethical Standards}

Funding This study was sponsored by AstraZeneca. Medical writing assistance was provided by Claire Woon PhD from AMICULUM Ltd, funded by AstraZeneca.

Conflict of interest HM and CB are employees of AstraZeneca. FA worked as a consultant for AstraZeneca. TM has participated in advisory roles for AstraZeneca and Eli Lilly and received honoraria from AstraZeneca and Eli Lilly. TSKM is the Principal Investigator for the AURA3 trial (NCT02151981). JC-HY has received honoraria for participating in advisory boards for Astellas, AstraZeneca, Bayer, Boehringer Ingelheim, Celgene, Clovis Oncology, Eli Lilly, Merck Serono, Merck Sharp \& Dohme (MSD), Novartis, Ono Pharmaceutical, Pfizer, Roche/Genentech/Chugai and Yuhan. CH is an employee of AstraZeneca and owns shares in AstraZeneca.
Open Access This article is distributed under the terms of the Creative Commons Attribution-NonCommercial 4.0 International License (http://creativecommons.org/licenses/by-nc/4.0/), which permits any noncommercial use, distribution, and reproduction in any medium, provided you give appropriate credit to the original author(s) and the source, provide a link to the Creative Commons license, and indicate if changes were made.

\section{References}

1. Lee CK, Wu YL, Ding PN, Lord SJ, Inoue A, Zhou C, et al. Impact of specific epidermal growth factor receptor (EGFR) mutations and clinical characteristics on outcomes after treatment with EGFR tyrosine kinase inhibitors versus chemotherapy in EGFR-mutant lung cancer: a meta-analysis. J Clin Oncol. 2015;33:1958-65.

2. Mok TS, Wu Y-L, Thongprasert S, Yang CH, Chu DT, Saijo N, et al. Gefitinib or carboplatin-paclitaxel in pulmonary adenocarcinoma. N Engl J Med. 2009;361:947-57.

3. Sequist LV, Yang JC, Yamamoto N, O'Byrne K, Hirsh V, Mok $\mathrm{T}$, et al. Phase III study of afatinib or cisplatin plus pemetrexed in patients with metastatic lung adenocarcinoma with EGFR mutations. J Clin Oncol. 2013;31:3327-34.

4. Yu HA, Arcila ME, Rekhtman N, Sima CS, Zakowski MF, Pao $\mathrm{W}$, et al. Analysis of tumor specimens at the time of acquired resistance to EGFR-TKI therapy in 155 patients with EGFRmutant lung cancers. Clin Cancer Res. 2013;19:2240-7.

5. Balak MN, Gong Y, Riely GJ, Somwar R, Li AR, Zakowski MF, et al. Novel D761Y and common secondary T790M mutations in epidermal growth factor receptor-mutant lung adenocarcinomas with acquired resistance to kinase inhibitors. Clin Cancer Res. 2006;12:6494-501.

6. Kobayashi S, Boggon TJ, Dayaram T, Janne PA, Kocher O, Meyerson M, et al. EGFR mutation and resistance of non-smallcell lung cancer to gefitinib. N Engl J Med. 2005;352:786-92.

7. Kosaka T, Yatabe Y, Endoh H, Yoshida K, Hida T, Tsuboi M, et al. Analysis of epidermal growth factor receptor gene mutation in patients with non-small cell lung cancer and acquired resistance to gefitinib. Clin Cancer Res. 2006;12:5764-9.

8. Sequist LV, Waltman BA, Dias-Santagata D, Digumarthy S, Turke AB, Fidias P, et al. Genotypic and histological evolution of lung cancers acquiring resistance to EGFR inhibitors. Sci Transl Med. 2011;3:75ra26.

9. de Boer RH, Arrieta Ó, Yang C-H, Gottfried M, Chan V, Raats J, et al. Vandetanib plus pemetrexed for the second-line treatment of advanced non-small-cell lung cancer: a randomized, doubleblind Phase III trial. J Clin Oncol. 2011;29:1067-74.

10. Ellis PM, Shepherd FA, Millward M, Perrone F, Seymour L, Liu $\mathrm{G}$, et al. Dacomitinib compared with placebo in pretreated patients with advanced or metastatic non-small-cell lung cancer (NCIC CTG BR.26): a double-blind, randomised, phase 3 trial. Lancet Oncol. 2014;15:1379-88.

11. Fossella FV, DeVore R, Kerr RN, Crawford J, Natale RR, Dunphy F, et al. Randomized phase III trial of docetaxel versus vinorelbine or ifosfamide in patients with advanced non-smallcell lung cancer previously treated with platinum-containing chemotherapy regimens. The TAX 320 Non-Small Cell Lung Cancer Study Group. J Clin Oncol. 2000;18:2354-62.

12. Hanna N, Shepherd FA, Fossella FV, Pereira JR, De Marinis F, von Pawel J, et al. Randomized phase III trial of pemetrexed versus docetaxel in patients with non-small-cell lung cancer previously treated with chemotherapy. J Clin Oncol. 2004;22:1589-97. 
13. Hata A, Katakami N, Yoshioka H, Fujita S, Kunimasa K, Nanjo $\mathrm{S}$, et al. Erlotinib after gefitinib failure in relapsed non-small cell lung cancer: clinical benefit with optimal patient selection. Lung Cancer. 2011;74:268-73.

14. Herbst RS, Sun Y, Eberhardt WE, Germonpre P, Saijo N, Zhou $\mathrm{C}$, et al. Vandetanib plus docetaxel versus docetaxel as secondline treatment for patients with advanced non-small-cell lung cancer (ZODIAC): a double-blind, randomised, phase 3 trial. Lancet Oncol. 2010;11:619-26.

15. Janjigian YY, Smit EF, Groen HJ, Horn L, Gettinger S, Camidge DR, et al. Dual inhibition of EGFR with afatinib and cetuximab in kinase inhibitor-resistant EGFR-mutant lung cancer with and without T790M mutations. Cancer Discov. 2014;4:1036-45.

16. Kawaguchi T, Ando M, Asami K, Okano Y, Fukuda M, Nakagawa $\mathrm{H}$, et al. Randomized phase III trial of erlotinib versus docetaxel as second- or third-line therapy in patients with advanced non-small-cell lung cancer: Docetaxel and Erlotinib Lung Cancer Trial (DELTA). J Clin Oncol. 2014;32:1902-8.

17. Shepherd FA, Dancey J, Ramlau R, Mattson K, Gralla R, O'Rourke M, et al. Prospective randomized trial of docetaxel versus best supportive care in patients with non-small-cell lung cancer previously treated with platinum-based chemotherapy. J Clin Oncol. 2000;18:2095-103.

18. Thatcher N, Chang A, Parikh P, Rodrigues PJ, Ciuleanu T, von Pawel J, et al. Gefitinib plus best supportive care in previously treated patients with refractory advanced non-small-cell lung cancer: results from a randomised, placebo-controlled, multicentre study (Iressa Survival Evaluation in Lung Cancer). Lancet. 2005;366:1527-37.

19. Janne PA, Yang JC, Kim DW, Planchard D, Ohe Y, Ramalingam SS, et al. AZD9291 in EGFR inhibitor-resistant non-small-cell lung cancer. N Engl J Med. 2015;372:1689-99.

20. European Medicines Agency. EMA fast-tracks new oral treatment for non-small cell lung cancer. Available at: http://www. ema.europa.eu/ema/index.jsp?curl=pages/news_and_events/news/ 2015/12/news_detail_002448.jsp\&mid=WC0b01ac058004d5c1. Accessed 21 Sept 2017.

21. Greig SL. Osimertinib: first global approval. Drugs. 2016;76:263-73.

22. Yang J, Ramalingam SS, Janne PA, Cantarini M, Mitsudomi T. LBA2_PR: osimertinib (AZD9291) in pre-treated pts with T790M-positive advanced NSCLC: updated Phase 1 (P1) and pooled Phase 2 (P2) results. J Thorac Oncol. 2016;11:S152-3.

23. AstraZeneca. Tagrisso met primary endpoint in phase III 2 nd-line lung cancer trial. Available at: https://www.astrazeneca.com/mediacentre/press-releases/2016/Tagrisso-met-primary-endpoint-in-phaseIII-2nd-line-lung-cancer-trial-18072016.html. Accessed 21 Sept 2017.

24. Mok TS, Wu YL, Ahn MJ, Garassino MC, Kim HR, Ramalingam SS, et al. Osimertinib or platinum-pemetrexed in EGFR T790positive lung cancer. N Engl J Med. 2017;376:629-40.

25. Soria JC, Wu YL, Nakagawa K, Kim SW, Yang JJ, Ahn MJ, et al. Gefitinib plus chemotherapy versus placebo plus chemotherapy in EGFR-mutation-positive non-small-cell lung cancer after progression on first-line gefitinib (IMPRESS): a phase 3 randomised trial. Lancet Oncol. 2015;16:990-8.

26. Soria JC, Kim S-W, Wu YL, Nakagawa K, Yang JJ, Ahn M-J, et al. Gefitinib/chemotherapy vs chemotherapy in EGFR mutation-positive NSCLC after progression on 1st line gefitinib (IMPRESS study): final overall survival (OS) analysis. Ann Oncol. 2016;Abstr. 12010.

27. Williamson JE, Forbes A. Introduction to propensity scores. Respirology. 2014;19:625-35.

28. Sturmer T, Rothman KJ, Avorn J, Glynn RJ. Treatment effects in the presence of unmeasured confounding: dealing with observations in the tails of the propensity score distribution-a simulation study. Am J Epidemiol. 2010;172:843-54.

29. Goldberg SB, Oxnard GR, Digumarthy S, Muzikansky A, Jackman DM, Lennes IT, et al. Chemotherapy with erlotinib or chemotherapy alone in advanced non-small cell lung cancer with acquired resistance to EGFR tyrosine kinase inhibitors. Oncologist. 2013;18:1214-20.

30. Gridelli C, Ciardiello F, Gallo C, Feld R, Butts C, Gebbia V, et al. First-line erlotinib followed by second-line cisplatin-gemcitabine chemotherapy in advanced non-small-cell lung cancer: the TORCH randomized trial. J Clin Oncol. 2012;30:3002-11.

31. Maemondo M, Inoue A, Kobayashi K, Sugawara S, Oizumi S, Isobe $\mathrm{H}$, et al. Gefitinib or chemotherapy for non-small-cell lung cancer with mutated EGFR. N Engl J Med. 2010;362:2380-8.

32. Miller VA, Hirsh V, Cadranel J, Chen YM, Park K, Kim SW, et al. Afatinib versus placebo for patients with advanced, metastatic non-small-cell lung cancer after failure of erlotinib, gefitinib, or both, and one or two lines of chemotherapy (LUX-Lung 1): a phase $2 b / 3$ randomised trial. Lancet Oncol. 2012;13:528-38.

33. Wang M, Zhao J, Zhang LM, Li H, Yu JP, Ren XB, et al. Combined erlotinib and cetuximab overcome the acquired resistance to epidermal growth factor receptors tyrosine kinase inhibitor in non-small-cell lung cancer. J Cancer Res Clin Oncol. 2012;138:2069-77.

34. Wu WS, Chen YM. Re-Treatment with EGFR-TKIs in NSCLC patients who developed acquired resistance. J Pers Med. 2014:4:297-310.

35. Wu YL, Liao ML, Qin SK, Sun Y, Zhou CC. Efficacy and safety of erlotinib in the treatment for advanced non-small cell lung cancer in Chinese patients. Zhonghua Zhong Liu Za Zhi. 2010;32:148-51.

36. FDA. Osimertinib FDA approval. Available at: http://www.fda. gov/Drugs/InformationOnDrugs/ApprovedDrugs/ucm472565.htm. Accessed 21 Sept 2017.

37. AstraZeneca. Tagrisso ${ }^{\mathrm{TM}}$ (osimertinib) approved in Japan for patients with EGFR T790M mutation-positive metastatic nonsmall cell lung cancer. Available at: https://www.astrazeneca. com/media-centre/press-releases/2016/tagrisso-approved-in-japanfor-patients-with-egfr-t790m-mutation-positive-metastatic-nonsmall-cell-lung-cancer-29032016.html. Accessed 21 Sept 2017.

38. Oxnard GR, Thress KS, Alden RS, Lawrance R, Paweletz CP, Cantarini $\mathrm{M}$, et al. Association between plasma genotyping and outcomes of treatment with osimertinib (AZD9291) in advanced non-small-cell lung cancer. J Clin Oncol. 2016;34:3375-82.

39. Thress KS, Brant R, Carr TH, Dearden S, Jenkins S, Brown H, et al. EGFR mutation detection in ctDNA from NSCLC patient plasma: a cross-platform comparison of leading technologies to support the clinical development of AZD9291. Lung Cancer. 2015;90:509-15. 